\title{
Against robot taxes: scrutinizing the moral reasons for the preservation of work
}

\author{
Elias Moser $^{1}$ (D) \\ Received: 10 March 2021 / Accepted: 1 May 2021 / Published online: 15 May 2021 \\ (c) The Author(s) 2021
}

\begin{abstract}
A recent political proposal to address the challenge of technological unemployment suggests that the state should impose a tax on labor-replacing technologies. The idea is to preserve jobs by disincentivizing automation. In this article, I critically assess the proposal from an ethical perspective. I show that, with respect to conceptions of distributive justice, it is unclear that precluding consumers' potential real-income gains from automation can be justified. But foremost, I examine the moral ideal behind the normative claim to preserve labor. I show that the arguments in favor of a robot tax rely on doubtful moral convictions on the value of work and I conclude that a moral basis for imposing a robot tax is subject to justified scrutiny.
\end{abstract}

Keywords Technological unemployment $\cdot$ Automation tax $\cdot$ Distributive justice $\cdot$ Value of work $\cdot$ Universal basic income

\section{Introduction}

Distinguished economists have argued that the number of jobs could soon be taken over by artificial intelligence AI [1]. Smart robots and computer programs are more efficient, make fewer mistakes, guarantee a higher quality of the outcome, and are (or tend to become) significantly cheaper than humans. Therefore, the implementation of AI in production processes is said to pose a major threat to many jobs [2]. In an oft-cited working paper on the US labor market, Carl Frey and Michael Osborne [3] estimate that around 50\% of today's jobs in the US are at risk of extinction. Not only industrial workers could soon be replaced by smart robots, but also many jobs in the service sector. AI can be programmed to be self-learning and adapt its functions to new conditions. Already today, many robots and algorithms no longer require human input [4].

There are, however, strong reasons put forward by economists that technological progress does not lead to mass unemployment $[4,5]$. Technological progress consists not only in replacing work with machines- "process innovation"-but also in the development of new marketable

Elias Moser

elias.moser@uni-graz.at

1 Section Moral and Political Philosophy, Institute of Philosophy, Karl-Franzens University of Graz, Attemsgaße 25/II, 8010 Graz, Austria goods- "product innovation" [6, 7]. In the course of the history of industrialization, these two developments went hand in hand. Roughly the same number of jobs lost in one sector was created in new sectors where new products were manufactured and sold. This development process is the root cause of long-term economic growth [8,9]: over time, the amount of affordable goods increases significantly, while demand for labor remains stable. Nevertheless, progress is not without sacrifice. Due to process innovations, there is socalled "structural unemployment": people who are replaced by machines have to apply for jobs in other sectors. They have to acquire new skills and adapt to new circumstances and they cannot find work during this transition period.

Pessimistic scenarios for the development of the labor market predict that the creation of new employment opportunities cannot keep up with the pace of new inventions. Arguably, the technological development of AI has a different impact on our economic system than other technologies before [10]. While earlier economic revolutions have allowed production processes to continuously adapt to new technologies, the pace of development of AI could outpace the adjustment process. Automation could move so fast that labor markets may no longer be able to absorb the free labor force. It could lead to vast "technological unemployment" TU.

Numerous proposals have been made to meet this challenge. In this article, I will discuss one particular political option to respond to the threat of mass technological 
unemployment-the so-called "robot tax" RT. The European Parliament recently discussed a proposal to introduce RT [11] and, in August 2017, the South Korean government has confirmed its intention to tax automation [12]. The proposal is also hotly debated in the public. Illustrious entrepreneurs, such as Bill Gates, opted for the idea of RT: "The robot that takes your job should pay taxes." [13]

The idea of RT is simple: to impose a tax on labor-replacing technologies to set a disincentive for automation and the replacement of human labor. The tax achieves its goal if it can slow down the replacement of human labor and allow employees to adapt to new circumstances and find new employment opportunities. As I will show in this article, however, from an ethical perspective RT is not beyond doubt.

I will argue that a robot tax is to be viewed critically with respect to fairness and with respect to its underlying normative assumption that work is a value that needs to be preserved. I will proceed in three steps. In the next section "Robot taxes and economic costs", I will say something about the economic costs of RT. In "Some considerations of justice", I argue that, from the point of view of distributive justice, it is difficult to justify the imposition of these economic costs on consumers. In "Distributive policies and the value of work", I take a step back and ask whether it is desirable at all to protect employment from automation, and outline a prominent argument for this protection, which relies on the assumption of an intrinsic value of work. This argument is then criticized in "Conclusion". I will show that the normative assumption of a value of work does not necessarily hold for the future.

\section{Robot taxes and economic costs}

In his famous book Software Society, William Meisel [14] explains the dual function of RT:

It (...) serves two purposes: (1) it provides an incentive for a company to create jobs by means such as investing in human-computer synergy; and (2) it proves governmental revenues that, properly used, can create more consumption and thus boost the economy. (p. 220)

As for every other tax, there are two separate concerns: (1) the incentives it sets and (2) the revenue it generates. These concerns can be studied separately. On the one hand, desirable incentives can be set, even if the tax does not generate revenue at all. On the other hand, government spending can also be financed by a tax, which generates large revenues but little incentive. Moreover, (2) is negatively correlated with (1): the better the tax incentivizes individual behavior, the less revenue the tax generates. My focus in this article is on taxing automation as (1) a tool to discourage and slow down the implementation of labor-reducing technologies because the challenge of TU only calls for RT as a disincentivizing tax for automation.

One could argue that RT is desirable because the state could raise funds to finance a redistributive scheme that compensates individuals for their job loss due to automation. Indeed, it is important to ask how a state could finance subsidies for individuals to insure them against TU. But the fact that $\mathrm{RT}$ raises funds is no sufficient argument to introduce it. As a matter of fact, every tax creates revenue. A supporter of RT would have to formulate an additional argument to justify the imposition of RT instead of any other form of taxation. Therefore, my aim is not to assess RT based on the desirability of its revenue. ${ }^{1}$

In their well-elaborated account on RT, Ryan Abbot and Bret Bogenschneider [15] introduce different ways of setting disincentives to replace human labor:

-Eliminating tax privileges: to "disallow the respective corporate income tax deductions for capital investment that give rise to the automation tax benefit" (p. 169)

-Taxing replacement: an "additional Federal tax to the extent the Treasury department determined the lay-offs were due to automation" (p. 170)

-Subsidizing labor: "tax preferences for firms that employ human workers for each category of tax benefit" (p. 171)

-Taxing capital: to "significantly increase the corporate tax rate" (p. 172)

One normative claim that lays at the heart of Abbot's and Bogenschneider's defense of RT is based on the observation that, on the one end, labor is highly taxed whereas, on the other, capital is usually not [16]. Their normative claim for $\mathrm{RT}$, therefore, relies on its presumed objective to neutralize the "competitive advantage" of robots over humans. They regard this asymmetry as an injustice $[17,18]$.

I am very sympathetic with this view, but the argumentation in this article does not rely on the idea of an unjustified advantage of capital owners over working people. The fact that capital owners are privileged over workers by the tax system would justify much more than simply RT. Numerous other taxes could be argued for, e.g., taxes on dividends or financial transaction taxes, etc. So, the Abbot's and Bogenschneider's argument does not specifically support RT. My aim is to discuss the taxation of automation exclusively as

\footnotetext{
${ }^{1}$ Furthermore, RT would need to be supplemented with obligations on the part of the government about how to spend the tax income. Otherwise, the money could well be spent for other purposes.
} 
an instrument to save jobs, which does not presuppose equal taxation of capital and labor.

It is worth noting, these different sorts of RT, especially taxing replacement and subsidizing labor, require a wealth of information to distinguish labor-replacing investments from other forms of capital inputs. Companies may be reluctant to provide information or look for ways to disguise their investments in labor-replacing technologies to avoid taxes. I am unable to judge whether or which sort of RT is legally feasible or leads to increased tax evasion. Therefore, my aim is not to criticize RT on these grounds. However, to assess the implications of RT from an ethical point of view, some observations should be made on its economic impact.

In the short term, slowing down automation could indeed save many jobs. Many hardships of people could be avoided who would otherwise need to adjust their career prospects. Employees who are replaced by machines have to adapt to the new circumstances on the labor market. They have to acquire new skills and competencies. For some people, automation is even devastating; they are unable to find new positions and become long-term unemployed. It is therefore a viable and often applied political option to delay the process of job replacement of work. For example, in the public sector, many bureaucratic processes that could in fact be assumed by computer programs to remain assigned to human officials. In the private sector, trade unions sometimes succeed in negotiating for temporary prevention of the use of specific labor-replacing technologies in their industry [19].

In the long run, however, product development creates new employment opportunities, and the temporary mismatch between the employee's skill profile and the requirements of the job can be overcome. From this long-term perspective, there are strong instrumental reasons not to hinder the introduction of new technologies into the production processes:

Imagine a country that taxes the application of a specific labor-saving technology while its surrounding trading partners refrain from imposing such a restriction. As a result, the other economies become more competitive as they can export their goods at lower prices. The domestic industry would therefore suffer a decrease in demand. The jobs which are protected from technological progress by RT are now threatened by international competition [20]. The state could continue to protect its companies from international competition with the help of import regulations or customs tariffs. But this policy has two undesirable effects. First, those employed in the protected sector are relatively unproductive. They could create more economic value by working on other jobs. Second, the tax is likely to be fully passed on to the consumers through price increases, which reduces their real income.

Taxing technology is economically costly and, after all, it is the consumers who bear the cost. If automation is not taxed, the implementation of process innovation technology would in fact lead to a significant reduction in prices. But if the use of technology is prevented, potential pricereductions cannot occur. Now, the question from a viewpoint of distributive justice is the following: Is it justified to favor employees over consumers? ${ }^{2}$

\section{Some considerations of justice}

Let me briefly discuss three prominent approaches to distributive justice and examine their respective answers to the question of whether we should impose a tax on automation to save jobs at the expense of consumers. I will show that none of the three theories of justice discussed can provide a clear-cut answer.

\subsection{Egalitarian justice}

There might be good reasons to charge consumers in order to save employment, because those individuals who lose their job concede a substantial loss of their income that, by far, outweighs the loss of the potential real income increase. Automation creates inequality. From an egalitarian perspective, RT can be justified if, compared to other policies, it leads to a more equal distribution. I understand egalitarianism to be a doctrine that advocates a higher degree of equality of income and wealth among individuals [21]. The underlying conception is thus purely distributive. I am not concerned with egalitarianism as a theory of how people should treat or relate to each other [22, 23].

To an egalitarian defendant of RT two questions can be asked:

(1) Is preserving employment more desirable than compensating individuals for their inability to work? Is RT a better option than redistributive policies that insure people against financial loss through unemployment?

(2) If there is a cost to maintain employment, who should pay for it, such that, overall, the redistribution leads to a more just outcome?

In the next section, I will present arguments to answer (1) affirmatively. These arguments rely on the assumption of a value of work that cannot be compensated for by means of financial subsidies. In this section, I will critically reflect RT's answer to question (2) that it should be the consumers to bear the cost. I believe that the egalitarian should be

\footnotetext{
2 These two groups are, of course, not exclusive. Extensionally they are quite similar, as all employees are consumers and most consumers have a job.
} 
hesitant to answer that the costs should be borne by the consumers.

With regard to distributive equality, taxes that increase consumer prices are among the most unfair forms of taxation: the poor spend almost all their income on consumption, while the rich can save money, invest, and thus evade the tax. RT does not necessarily increase prices for goods, but it deters the implementation of cost-saving technologies and thus rules out potential decreases in prices. These potential decreases would benefit the working class more than those who do not spend their entire income on consumption. From a viewpoint of egalitarian justice, I believe, RT would not be supported as the best option to meet the challenge of TU.

It is true that in the short term, the inequality resulting from unemployment is potentially worse than that resulting from the loss of consumer real income. But, in the long run, discouraging process innovation is very detrimental to everyone's economic well-being. Process innovation leads to a substantial reduction in production costs. Employees, who were formerly needed in the production of goods that now can be produced by machines are able to perform other tasks and their labor can be used to produce new goods.

Again, technological progress is the most important factor for economic growth and the creation of material wealth. Egalitarians who state that we should favor the preservation of jobs over technological progress might run afoul of what is called the "levelling-down objection" [24]: For the purpose of equality, they are willing to accept that everyone is in a worse position. To avoid this outcome, the egalitarian defendant of RT should not be critical towards technological progress. It is not desirable to exclude or hinder technological progress because, eventually, everyone is at risk of being worse-off.

\subsection{Priority and sufficiency}

Let me consider two other forms of theories of distributive justice, which try to distinguish themselves from egalitarianism. Prioritarianism differs from egalitarianism in that it does not assume that the equal distribution of resources, income, welfare, etc. have an intrinsic value. Instead, those who have less should be given preference in distribution, while those who have more should not be given priority [24]. In a similar vein, so-called Sufficientarianism argues against the intrinsic value of equal distribution [25, 26]. Harry Frankfurt criticizes egalitarianism with his famous "life-boat example" [27]. If there is not enough life-boat seats on a sinking ship, distributing seats equally would lead to disaster. Instead of saving the lucky ones who get a seat, no one should be saved. Frankfurt suggests that a distributor's goal should be to have as few people as possible fall below a threshold. Sufficiency should be the exclusive (primary) aim of distributive justice.
Of course, all employees are also consumers, and most consumers are also employees. But becoming unemployed is by far worse than being deprived of some consumption opportunities. Therefore, there is both a prioritarian and a sufficientarian claim for RT. On the one hand, to protect people from losing their job at the expense of consumers is fair from a prioritarian perspective, since it gives priority to those who suffer more. On the other hand, the protection of jobs can also be seen as important from a sufficientarian perspective, if we assume that those losing their job usually fall below a threshold of sufficiency.

However, the argument is insufficient to justify RT. Neither prioritarian nor sufficientarian accounts identify a substantive moral difference between protecting a job and compensating an individual for not having a job. A person might as well be paid a minimum income so that he or she is able to cover his or her expenses and live a decent life. To justify the moral priority of the protection of labor over redistribution, one would need to assume a value of work that cannot be compensated for with governmental subsidies. I consider such an argument in the next section.

One could object here that a redistributive scheme protecting people against the loss of income through vast TU is expansive and that it leads to an increase in taxes. Now, the group of taxpayers is almost identical to the group composed of consumers. Arguably, therefore, those who object to RT because it increases consumers prices (and reduces real income) would also have to object to a redistributive scheme that leads to an increase in taxes. However, it should be noted that while the two groups are extensively similar, the tax burden due to RT hits the poorer harder than the rich. In contrast, income taxes or capital taxes to finance redistribution can be based on earnings. As I mentioned above, taxes that raise consumer prices are among the most unfair. Especially, from a prioritarian view, RT seems not to be fair-it saves jobs at the expense of the poor.

\subsection{Harm and desert}

There is an argument in favor of slowing-down process innovation, which does not necessarily rely on an idea of distributive justice. The claim for RT could be backed with a morally significant distinction between 'harm' and 'not benefitting.' Becoming unemployed can be conceived of as harm whereas not benefitting from a potential price reduction (because of lower production costs) is not. Therefore, a principle of "non-maleficence" [28] could be supportive of RT. To avoid harm to employees who are at risk of replacement, it would be justified to impose a tax.

Let us admit for the moment that the assumption behind this argument is true and there is a morally significant difference between being harmed and not benefitting. Still, the problem remains that the argument does not show why we 
should save jobs through taxes and that it should be the consumers to bear the cost of this presumed harm prevention. It is not the case that consumers deserve taxation in any way. Consumers have not made the unemployed lose their jobs. I do not think it is an ethically defendable position that consumers violate a moral duty by not paying higher prices for human-made goods and services instead of buying goods and services produced by smart robots and AI.

An attempt to justify charging consumers is with reference to a so-called "beneficiary-pays principle," which is often proposed to distribute the costs of mitigation of climate change [29]. It holds that, states that benefit from a past injustice - the unsustainably large amount of greenhouse gas emissions - should pay for the costs of climate change. Analogously, consumers could be taxed since they otherwise benefit from the presumably unjust replacement of jobs. However, I believe that this principle cannot be supported without major refinement. There are numerous ways in which one may benefit from the injustices committed by others without having a moral obligation to compensate those who suffer from it.

But even if a more precise form of the principle can be defended, it does not seem to apply to the problem of TU. We cannot identify a specific action that constitutes an injustice toward the unemployed. In general, it is difficult to find any particular agent worthy of blame and owing compensation to the unemployed: One might say that inventors of new technology are actually doing humanity a favor with finding ways to reduce human effort to produce goods, entrepreneurs are forced to choose efficient means of production through market competition, and shareholders are entitled to the returns of smart investments in efficient businesses.

Of course, entrepreneurs and shareholders can, to some extent, be held morally responsible for ruthless decisions that cause many layoffs. In specific cases, there is cause for blame. However, these cases do not support the claim, that every implementation of labor-replacing technologies is unjust. In general, automation is not an injustice and consumers are, therefore, not unjustified beneficiaries of injustices.

RT leads to a redistribution of people's real income to secure jobs. The harm principle only justifies measures to avoid job losses but it does not justify that we do so in excluding potential benefits for all consumers. The principle cannot sufficiently justify RT. So, the defendants of RT would have to provide additional arguments to show that placing the tax burden on consumers is justified.

But even if temporarily saving employment with the help of RT can be justified with reference to an ideal of distributive justice, one might ask whether unemployment necessarily constitutes harm. In the following passage, I want to go one step back and ask the question if preserving work is a valuable end at all. I will outline different ideas to support of securing labor that conceive of work as a constitutive part of the good life.

\section{Distributive policies and the value of work}

Obviously, work is necessary to create an income, satisfy needs, achieve well-being, or pursue a good life. But if this instrumental value were the only value of work, distributive policies could perfectly compensate for the loss of labor. Traditional policies to ensure people's ability to satisfy their needs against unemployed are, first, unemployment insurances and, second, social welfare schemes.

Unemployment insurance: is not designed as longterm support of people who become unemployed but only for temporal ease of financial losses due to temporary unemployment. Such an insurance cannot accommodate a large increase in long-term unemployment due to automation. A public insurance regime could not guarantee financial subsidies unless there is a heavy increase in premiums. When long-term TU occurs and people need to be insured against more than just temporary losses, the unemployment insurance does not substantially differ from a social welfare scheme.

Social welfare: is for many reasons unattractive. In most welfare states there are circumstances which (intentionally or not) deter individuals from becoming dependent on the social insurance scheme. To receive subsidies, individuals are often forced to abandon a substantial amount of their liberties, they are forbidden to travel, unfree to choose where to live, they are supervised and, sometimes, even forced to participate in work programs. Importantly, there are also deterrent factors due to social pressure. People become stigmatized, socially excluded, and marginalized. In this sense, social welfare schemes do not fully compensate individuals for the loss of work opportunities. Governments also struggle to overcome what may be called a "poverty trap" which is inherent to social aid: Once dependent on social security, people have less incentive to work: the more they earn the less they receive from the state.

These reasons might support the case for RT, since traditional redistributive policies are particularly ill-suited to meet the challenge of TU. However, there are other redistributive policies that could avoid these problems. Many scholars argue that the challenge of TU calls for an implementation of an Unconditional Basic Income UBI [30, 31] - a redistributive scheme that guarantees each member of society a periodical payment that is unconditional upon their abilities, their specific circumstances, and, foremost, upon the additional income they generate through work. The UBI substantially increases people's liberty to enter into those working relationships they really want to and it 
increases the bargaining power of individuals in negotiations on the terms of their employment. Individuals are no more forced economically to accept any job. In the light of the threat of TU, the UBI, therefore, has many advantages over traditional distributive policies [20, 32].

If the problem of TU can be solved only with the help of distributive policies that do not aim at securing jobs, the question is why we should impose RT. Put differently, the question is the following: does work possess a value that cannot be compensated for with the help of financial subsidies?

\subsection{Work and the good life}

There are prominent ethical and political reasons that speak in favor of preserving employment. ${ }^{3}$ The ability to work is not only seen as an instrumental value - a necessary means to create income to secure needs-satisfaction and the pursuit of happiness. It can also be conceived of as an intrinsic value-as an element of the good life: Even if our society is able to overcome problems of a loss of income, of serious inequalities, and poverty, the lack of opportunity to work hinders individuals from living a fulfilled and meaningful life. Work is often seen as a constitutive part of individual conceptions of a good life. If that is the case, redistribution of income cannot fully compensate the unemployed for their loss. Let me briefly introduce three different aspects of the goods of work beyond income.

Excellence: Anca Gheaus and Lisa Herzog [34] identify a specific value of work in the attainment of excellence. According to them...

[e]xcellence includes the development of one's skills—for example, good judgement—but also the accomplishments resulting from the exercise of these skills-for example a good piece of craftsmanship. (p.

74)

As Gheaus and Herzog argue, excellence refers to the relation of a person with the outcome of his or her productive actions. An essential component is the development of one's own skill through practice. Since most of people's productive activities are carried out in the workplace, labor is the primary source for achieving excellence, thus conceived. It is at the workplace where individuals are able to develop their skills.

As Michele Loi [35] argues, lacking the ability to work due to automation may "disenhance" people. They become incapable of developing their full capacities. Ultimately, disenhancement has a negative impact on the ability of individuals to pursue their life plans.

\footnotetext{
${ }^{3}$ For economic considerations see [33].
}

Self-respect: Exclusion from work has a particularly serious impact on individual's perception of themselves as a valuable member of society. The presence of self-respect is constitutive of a fulfilled life. According to John Rawls [36], self-respect is "perhaps the most important primary good" (p. 440). Therefore, it plays a central role in the literature on the moral dimensions of unemployment [37, 38].

A key factor for individual self-esteem is the ability to make a contribution to society that is effectively valued. For the vast majority of people, it can be assumed that work is the single and most important way to produce something that proves to be appreciated by others-i.e. the market value that the individual productivity achieves. Therefore, paid labor is central to achieving and maintaining self-esteem [39] and people who are deprived of work often lack selfrespect. They are disabled from contributing something of value to society.

Meaning in life: In his famous account on meaning in life, Thaddeus Metz [40] argues that we can achieve meaning when we either bring about morally good states of affairs, attain a true conception of reality, or produce objects of great aesthetic value - the good, the true, and the beautiful. Crucially, these states of affairs have to be achieved by our own actions: there must be a causal connection between what we do and what is happening in the world around us [41].

This causal component is of particular importance for the assessment of the value of work. Work is necessary for people to have an impact on their environment. Therefore, unemployment through automation poses a moral challenge as it leads to a potential loss of meaningfulness [42]. John Danaher and Sevn Nyholm discuss the problem that automation could lead to "achievement gaps" [43]. If robots take over most of the work formerly done by humans, individuals might be unable to produce something value. It is not the agent's causal contribution, his or her effort that is exerted through his or her own voluntary actions, that creates value. $\mathrm{TU}$ and $\mathrm{AI}$-induced automation may thus deprive individuals of being able to achieve something.

These three conceptions of the value of work-excellence, self-respect, and meaning in life-are not an exhaustive list of elements of the good life endangered by unemployment. However, the arguments in favor of preserving labor (based on these conceptions) all share the same structure: Engaging in paid labor is assumed to be the exclusive or, at least, the predominant way to attain these elements of the good life. The lack of employment opportunities is therefore shown to be morally bad, and the fact that it is bad is seen as a sufficient reason for the state to take action to create and secure job opportunities.

RT can thus be justified with respect to excellence, selfrespect, and meaning in life. As it is assumed that only work can help people pursue these goals, work needs to be preserved. A tax which disincentivizes the implementation of 
labor-saving technologies, therefore, secures the employee's conceptions of a good life.

\subsection{Critique}

These arguments have a strong intuitive appeal. As I will argue, however, they need to be reassessed in view of future developments and the possibility of vast TU $[44,45]$. There are two interdependent reasons that speak against the thesis that unemployment is bad because work is constitutive of the good life:

First, it can be scrutinized that work is a necessary component of a good life. Although individuals in general need to pursue paid labor to live a good life, this does not support the claim that everyone does so and, more importantly, that without work one cannot achieve excellence, self-esteem, and meaning in life.

Richard Arneson [37] argues that the lack of work cannot be financially compensated for because it is a central element of well-being that individuals cannot buy with money. He rightly assumes that being employed is not good that one can purchase. A mere subsidy, Arneson argues, is therefore not enough. To some extent, however, individuals can use subsidies to finance their productive lives, where they can achieve excellence, self-esteem, and meaning. Paid labor is not the only way to be productive [46].

Imagine only a person receiving an unconditional basic income, such that, instead of being required to work in a factory, she can open her own bookshop. Even if the shop is unprofitable, the person receives her monthly payment from the state. She is able to excel in that she can prove to the customers her exquisite taste of novels. She gains the respect of others and views herself as a valuable member of society. Ultimately, her work at the bookshop has an impact on others in that she can encourage more and more people to read and to introduce them to new literature.

As the example intends to show, the person is not disabled from leading a good life. Paid labor, in this case, is not necessary to achieve excellence, self-esteem, or meaning in life [44]. The fact that some people lack imagination about how to spend their time without working is, of course, worrisome. But it does not justify taxing automation with RT instead of distributive policies. Many people, rather than having their jobs protected, prefer to receive a monthly payment and being productive in the way they believe is beneficial to them and to others.

Second, it may be true in today's society that paid work is required for a good life. Nevertheless, this notion of a good life can also undergo a severe shift. Our assessment of unemployment could be susceptible to what is called a "technomoral change" [47, 48]. Technological progress can have a strong impact on our evaluative attitudes. Some values gain strength, while others lose significance.
This techno-moral shift is a problem for "bottom-up" ethical arguments, which either fully rely on moral intuitions [49] or on commonly held moral convictions. These arguments derive a value from nowadays observed moral beliefs and attitudes and argue for a specific assessment of a future event in referring to that value. In the case of the justification of an RT the problem is acute. We cannot take reference on nowadays convictions of the value of work to define its value in the future-a future in which it becomes scarce and perhaps far less important for our lives. It is to be assumed that today's predominant "work ethic" will be negatively influenced by automation.

Due to the techno-moral change, it is also the case that studies showing the negative effects of unemployment on mental and physical health are not a reliable source for estimating the value of work in the future. Nowadays, it is not necessary to look at the statistics to see that unemployment has a strong negative impact on people [50]. The unemployed are socially excluded, stigmatized. The fact that they do not have the opportunity to excel and gain the respect of others through work affects the psyche and ultimately causes health problems. However, it is questionable whether this connection can also be assumed for the future. The correlation is highly contingent upon current social values.

The normative case for protecting employment by means of RT is dependent on the premise of a value of work. If, however, the counterarguments show that such a value does not necessarily exist, the case for RT collapses. On the one hand, as I tried to argue, paid labor is not required to lead a good life. On the other hand, our common moral convictions on the value of work are an unreliable source to infer from them the value of work in the future. These two objections show that there are no reasons for the conviction that automation necessarily threatens excellence, self-esteem, meaning in life. We can imagine a person who does not work, but who nevertheless leads a fulfilling and meaningful life and considers herself a valuable member of society.

\section{Conclusion}

To address the challenge of technological unemployment $\mathrm{TU}$ in the advance of artificial intelligence, it was proposed to impose a robot tax RT to disincentivize automation and to preserve labor. In this article, I examined this proposal from an ethical perspective. I have shown that, from a viewpoint of distributive justice, charging consumers with the tax burden might be unjustified. A defendant of RT would need to further argue why it is justified to preserve labor at the expense of potential gains in real income through automation.

My second argument against the robot tax tackled the moral assumptions behind the normative conviction that RT 
is justified. I have shown that work does not necessarily possess an intrinsic value. To lead a good life, it is a priori not required to be able to pursue paid labor. Therefore, preservation of work by means of a RT is not necessarily a valuable end in its own right. The morally problematic features of increased unemployment can be avoided with the help of distributive policies such as social insurance or a universal basic income UBI.

Funding Open access funding provided by University of Graz.

Open Access This article is licensed under a Creative Commons Attribution 4.0 International License, which permits use, sharing, adaptation, distribution and reproduction in any medium or format, as long as you give appropriate credit to the original author(s) and the source, provide a link to the Creative Commons licence, and indicate if changes were made. The images or other third party material in this article are included in the article's Creative Commons licence, unless indicated otherwise in a credit line to the material. If material is not included in the article's Creative Commons licence and your intended use is not permitted by statutory regulation or exceeds the permitted use, you will need to obtain permission directly from the copyright holder. To view a copy of this licence, visit http://creativecommons.org/licenses/by/4.0/.

\section{References}

1. Brynjolfsson, E., McAfee, A.: The second machine age: work, progress, and prosperity in a time of brilliant technologies. Norton and Company, New York (2014)

2. Acemoglu, D., Restrepo, P.: Robots and Jobs: Evidence from US Labor Markets. NBER wp23285. http://www.journals.uchicago. edu/doi/full/10.1086/705716 (2017). Accessed 6 Mar 2021

3. Frey, C.B., Osborne, M.: The Future of Employment. Oxford Martin School WP. http://sep4u.gr/wp-content/uploads/The_Future_ of_Employment_ox_2013.pdf (2013). Accessed 6 Mar 2021

4. Autor, D.: Why are there still so many jobs? The history and future of workplace automation. J. Econ. Pers. 29, 3-30 (2015). https:// doi.org/10.1257/jep.29.3.3

5. Arntz, M., Gregory, T., Zierahn, U.T.: Digitization and the Future of Work: Macroeconomic Consequences. In: Zimmermann K.F. (ed.) Handbook of Labor, Human Resources and Population Economics, pp. 1-29. Springer, Cham (2020) https://doi.org/10.1007/ 978-3-319-57365-6

6. Vivarelli, M.: Innovation, employment and skills in advanced and developing countries: a survey of economic literature. J. Econ. Issues 48, 123-154 (2014). https://doi.org/10.2753/JEI00213624480106

7. OECD: ICTs and Jobs: Complements or Substitutes. Digital Economy WP259. https://doi.org/10.1787/5jlwnklzplhg-en (2016). Accessed 6 Mar 2021

8. Solow, R.M.: A contribution to the theory of economic growth. Q. J. Econ. 70, 65-94 (1956). https://doi.org/10.2307/1884513

9. Romer, D.: Advanced macroeconomics, 4th edn. McGraw-Hill, New York (2011)

10. Pratt, G.A.: Is a Cambrian explosion coming for robotics? J. Econ. Pers. 29, 51-60 (2015). https://doi.org/10.1257/jep.29.3.51

11. Reuters: European Parliament Calls for Robot Law, Rejects Robot Tax. https://www.reuters.com/article/us-europe-robots-lawma king/european-parliament-calls-for-robot-law-rejects-robot-taxidUSKBN15V2KM (02-12-2017). Accessed 6 Mar 2021
12. Sung-won, Y.: Korea Takes First Step to Introduce 'Robot Tax'. Korea Times. http://www.koreatimes.co.kr/www/news/techl2017/ 08/133_234312.html (08-07-2017). Accessed 6 Mar 2021

13. Delaney, K.: The Robot that Takes Your Job Should Pay Taxes, Says Bill Gates. Quartz. https://qz.com/911968/bill-gates-therobot-that-takes-your-job-should-pay-taxes/ (02-17-2017). Accessed 6 Mar 2021.

14. Meisel, W.: The software society: cultural and economic impact. Trafford, New York (2013)

15. Abbott, R., Bogenschneider, B.: Should robots pay taxes? Tax policy in the age of automation. Harv. L. Pol'y. Rev. 12, 145-175 (2018). https://doi.org/10.2139/ssrn.2932483

16. Acemoglu, D., Manera, A., Restrepo, P.: Does the US tax code favor automation? NBER wp27052. https://www.nber.org/papers/ w27052 (2020). Accessed 6 Mar 2021

17. Mazur, O.: Taxing the robots. Pepp. L. Rev. 46, 277-330 (2019)

18. Hemel, D.: Does the tax code favor robots? Ohio St. Tech. L. J. 16, 219-243 (2020)

19. Moon, C.A.: Technology, robotics, and the work preservation doctrine: future considerations for labor and management. Pepp. L. Rev. 14, 403-420 (1987)

20. Hughes, J.J.: A strategic opening for a basic income guarantee in the global crisis being created by AI, robots, desktop manufacturing and biomedicine. J. Evol. \& Technol. 24, 45-61 (2014)

21. Arneson, R.: Egalitarianism. In: Zalta, E.N. (ed.) The Stanford Encyclopedia of Philosophy (2013) https://plato.stanford.edu/ archives/sum2013/entries/egalitarianism/

22. Anderson, E.: What is the point of equality? Ethics 109, 287-337 (1999). https://doi.org/10.1086/233897

23. Gordon, J-S.: Moral Egalitarianism. In: Fieser, J. (ed.) Internet Encyclopedia of Philosophy (2007). https://iep.utm.edu/moral-eg/

24. Parfit, D.: Equality or Priority. Lindley Lectures 30. http://hdl. handle.net/1808/12405 (1991). Accessed 6 Mar 2021

25. Crisp, R.: Equality, priority, and compassion. Ethics 113, 745-763 (2003). https://doi.org/10.1086/373954

26. Casal, P.: Why sufficiency is not enough. Ethics 117, 296-326 (2007). https://doi.org/10.1086/510692

27. Frankfurt, H.: Equality as a moral ideal. Ethics 98, 21-43 (1987). https://doi.org/10.1086/292913

28. Ross, W.D.: The right and the good. Oxford University Press, New York (2002)

29. Butt, D.: On benefiting from injustice. Can. J. Phi. 37, 129-152 (2007). https://doi.org/10.1353/cjp.2007.0010

30. Roberts, K.: Automation, unemployment, and the distribution of income. European Centre for Work and Society, Maastricht (1982)

31. Walker, M.: BIG and technological unemployment: chicken little versus the economists. J. Evol. \& Technol. 24, 5-25 (2014)

32. Bruun, E.P., Duka, A.: Artificial intelligence, jobs and the future of work: racing with the machines. Basic Income Stud. 13, 1-15 (2018). https://doi.org/10.1515/bis-2018-0018

33. Marchant, G., Stevens, Y., Hennessy, J.: Technology, unemployment and policy options: navigating the transition to a better world. J. Evol. \& Technol. 24, 26-44 (2014)

34. Gheaus, A., Herzog, L.: The goods of work (other than money!). J. Soc. Phil. 47, 70-89 (2016). https://doi.org/10.1111/josp.12140

35. Loi, M.: Technological unemployment and human disenhancement. Ethics Inf. Technol. 17, 201-210 (2015). https://doi.org/ 10.1007/s10676-015-9375-8

36. Rawls, J.: A theory of justice. Harvard University Press, Cambridge (1971)

37. Arneson, R.: Is work special? justice and the distribution of employment. Am. Polit. Sci. Rev. 84, 1127-1147 (1990). https:// doi.org/10.2307/1963256

38. Moriarty, J.: Rawls, self-respect, and the opportunity for meaningful work. Soc. Theory \& Pract. 35, 441-459 (2009). https://doi. org/10.5840/soctheorpract200935325 
39. Elster, J.: Is there (or should there be) a right to work? In: Gutmann, A. (ed.) Democracy and the welfare state, pp. 62-63. Princeton University Press, Princeton (1988)

40. Metz, T.: The good, the true, and the beautiful: toward a unified account of great meaning in life. Rel. Stud. 47, 389-409 (2011). https://doi.org/10.1017/S0034412510000569

41. Wolf, S.: Happiness and meaning: two aspects of the good life. Soc. Phil. \& Pol'y. 14, 207-225 (1997). https://doi.org/10.1017/ S0265052500001734

42. Kim, T.W., Scheller-Wolf, A.: Technological unemployment, meaning in life, purpose of business, and the future of stakeholders. J. Bus. Ethics (2019). https://doi.org/10.1007/ s10551-019-04205-9

43. Danaher, J., Nyholm, S.: Automation work and the achievement gap. AI Ethics (2020). https://doi.org/10.1007/ s43681-020-00028-x

44. Danaher, J.: Will life be worth living in a world without work? Technological unemployment and the meaning of life. Sci. Eng. Ethics 23, 41-64 (2017). https://doi.org/10.1007/ s11948-016-9770-5

45. Danaher, J.: Automation and Utopia: human flourishing in a world without work. Harvard University Press, Cambridge (2019)
46. Kirchgässner, G.: Critical analysis of some well-intended proposals to fight unemployment. Anal. \& Krit. 31, 25-48 (2009)

47. Boenink, M., Swierstra, T., Stemerding, D.: Anticipating the interaction between technology and morality. Stud. Ethics L. \& Tech. 4, 1-38 (2010). https://doi.org/10.2202/1941-6008.1098

48. Lucivero, F., Swierstra, T., Boenink, M.: Assessing expectations: towards a toolbox for an ethics of emerging technologies. NanoEthics 5, 129-141 (2011). https://doi.org/10.1007/ s11569-011-0119-x

49. Stratton-Lake, P.: Intuitionism in Ethics. In: Zalta, E.N. (ed.) The Stanford Encyclopedia of Philosophy (2014). https://plato.stanf ord.edu/entries/intuitionism-ethics/

50. Prainsack, B., Buyx, A.: The value of work: addressing the future of work through the lens of solidarity.". Bioethics 32, 585-592 (2018). https://doi.org/10.1111/bioe.12507

Publisher's Note Springer Nature remains neutral with regard to jurisdictional claims in published maps and institutional affiliations. 